\title{
Problems and Suggestions of Food Safety Law
}

\author{
Shuhan $\mathrm{Qi}^{1, \text { a }}$ \\ Wuhan University, Wuhan 430072, China
}

Keywords: Environment protection, food, law, safety.

\begin{abstract}
The interactions between food production and environment protection afford us many instances, for example, the food event caused by pollution, or the environment disruption caused illegal food production. This essay catch sight of the connection of the food production or consumption and the environment, and point out four problems in national Food Safety Law, and contend that establishment of eight legal system like the permission of free and fair market entering, with the purpose of improvement of our Food Safety Law.
\end{abstract}

\section{Introduction}

In recent years, the problem of the environment is more and more serious, the environmental problems which influence the development of biodiversity, influence human living environment, environmental issues is associated with life. Take for example food safety issues, environment influence on food safety, food production and consumption also affect the environment.

The present research has shown that food safety problems caused by environmental problems are mainly focused on the water pollution, soil pollution and biological pollution. Environmental problems caused by food production and consumption, which mainly include change caused by chemical pollutants residues, pesticide residues and biological factors. Therefore, this article from the perspective of environmental protection, existing problems of current food safety law are studied, it is very urgent practical significance.

\section{Current Situation and Problems of China's Food Safety}

In recent years, China's food safety accident is more frequent. A series of problems constantly remind it is very urgent to solve the food safety problem, on the one hand, with the rapid development of food industry, food safety problems becomes more and more obvious. Since the $1990 \mathrm{~s}$, China's food industries develop rapidly, which has become the pillar industry of our country. In 2011, food enterprises above designated size are more than 31735 , total output value of food industry accounted for $9.1 \%$ national industrial total output value. In addition, new technologies, new resources in the application of food safety industry brought new risks to food safety, on the other hand, the safety problems are common in the food circulation of each link.

First, the source of pollution, our country is still developing countries, industrialization caused certain environmental pollution, these pollution endangers the source of food safety industry chain.

Second, the unsafe problems of production processing link exist, situation of some criminals adulterating and counterfeiting is serious, even use non-food raw materials, abuse additives to manufacture foods. Due to historical reasons in China, the manual and family processing methods occupy large proportion, the overall quality of industry and the mode of production are more original and low, these are inevitably will bring huge hidden danger to the environment and food safety.

Moreover, food safety circulation is not standard, the great part of our country food industry enterprises are small and disorderly, liquidity is great, and management is difficult. For example, food packaging, transport, storage process used unqualified packaging, antiseptic and preservative, these problems are easy to cause environmental damage, but it is difficult to supervise.

Finally, the industrial chain link is deficient. Our country agricultural distribution is very scattered, and the food market is gradually concentrated, which makes food from farmland to dining table prone to connection imbalances, there are a certain degree of dislocation in collection of raw materials, 
production processing and product marketing, link is not stable at the same time, Once food safety or environmental issues appears, it is difficult to trace to its source and more difficult to handle, then evoke unstable factor.

Therefore, as food safety and environmental safety more and more attract the public attention, it is necessary for us from the perspective of environmental protection, analyze and study food in the process of production, circulation face what specific risks and problems, sales, the responsibility and obligation should be determined, and guide the government, enterprises, social forces and individuals involved in action of economic activity of food safety in the future.

\section{The Existing Problems in China's Food Safety Law}

According to the above described food safety problem, the form is divided into the following categories: first, it is the food contamination, it manifests agricultural products fertilizer, pesticide excessive residues, animal by-products hormone, antibiotics abuse, the second is food production damage, it presents low production efficiency method are used in the process of food processing, cause environmental damage or resource exhaustion, the third is the circulation of food pollution, it manifests environmental damage risk caused by packaging, preservatives, the fourth is the food environmental risk, food from in the process of farmland to dining table, it is affected by environmental impact and cause food unsafe risks, environment is also in the food from farmland to dining table may suffer from the risk of damage.

Although "Food Safety Law of the People's Republic of China'" has passed in 2009 by, it has been aimed at food safety and issued a uniform code, the guidance effect of other laws, regulations and regulatory documents in the system is low, these disadvantages are solved to a certain extent, but as a legal system, there are many deficiency in the field of food safety legislation:

3.1 Lack of systematic property and coordination

At present, the food safety law system in our country, adjusting range of most articles is quite narrow, from the perspective of food is more, but it is not from the perspective of food safety and environmental safety to specify, therefore, a "from farmland to dining table" whole process are adjusted and specify, this system does not constitute, at the same time, from the point of the specific content of the law, regulations repetition and general phenomenon are prominent, and many of the articles are issued early, articles are relatively dispersive, such as "Product Quality Law of the People's Republic of China, Agriculture Law of the People's Republic of China" and so on, some profiles regulation are only made to food safety, standards requirements is low, () it is not fully reflect the consumer's food safety requirement at present stage, it more can't reflect the urgent need of the people for the environment safety the present stage.

3.2 Lack of operability

Our current food safety laws and regulations, some articles are relatively principle and broad, and restrictive law also not clear, its shortcomings are more and more exposed in practice, such as the planting, breeding, store and other links, the food and food additives that food related, feed and feed additives production, operation or use, though has a regulation, but too principle and sweeping, operational compatible system is not perfect. This makes the problems such as lagging behind supervision and weak regulation and so on. At the same time, many important contents of the food safety law is still blank, some important law content law widely adopted by the international community in recent years, such as food security crisis emergency treatment, unsafe food recall and treatment, major food safety accidents, food safety accident compensation and other important content has not been into the food safety law.

\subsection{Punishment deterrence is insufficient}

At present, "food safety law" on food safety in our country, article eighty-four, article eighty-five, article eighty-six and article eighty-seven has made specific provisions on legal responsibility that producer and proprietor who violate the food safety production law should bear. The food value of illegal production and operation is less than ten thousand yuan, in addition to the relevant administrative punishment, over two thousand yuan and below fifty thousand yuan are fined, value of 
ten thousand yuan are over, and be fined more than five times goods value or below ten times times goods value, if the circumstances are serious, the license are revoked. The amount are no effectively deterrent to food production seller, at the same time, also did not consider give attention damage caused by environment may at the same time, it is unable to effectively adjust the specific behavior of food production and seller.

\subsection{Legal liability is not perfect}

Under the condition of environmental damage and food safety at the same time, how to protect the appeal for consumers, there are many problems in the concrete practice, such as filing a case to hard, the amount of damages is difficult to estimate, it leads consumer demands to put forward hard, At the same time, and some national standards actually determined by the industry monopoly enterprises, public security interests is not on the first, and cause consumer demands rationality is difficult to be determined, third, in the field of food safety, only the food quality is unqualified, burden of proof by defendant can be done, cause the appeal cannot get support, fourth, problems caused by food safety or environmental damage, usually emerge after many years later, it has already exceed limitation of legal proceedings, more not to know about the exact source of the problem, this cause could not maintain demands by the judicial practice.

\section{Summary and Suggestions}

In view of the present situation of the food safety law system in our country, one of the basic principles of environmental protection should be as soon as possible---place risk prevention principle on the food safety law system, improve the relevant systems constantly, food safety and environmental safety problems are contained in source:

First, the food quality and safety market access legal system are established and improved, enterprises engaged in food production and processing need to have the corresponding basic conditions will be improved, mandatory food market access logo, etc. on the basis of implementing Good Manufacturing Practice (GMP), introduce "HACCP system" quickly, gradually promote enforcement process of "HACCP system", in all areas related to food safety and quality, and push forward food safety laws and regulations, technical specifications, guidelines and standards that our country related CAC, 150 group that has started to use, according to the "International Food Code", set up food safety standard system in line with principle that international food code commission make, fully monitor food safety, all the links in the food industry chain are set up standards and regulation, after China access WTO, reduce the gap with international standards and integrate with international practice smoothly.

Secondly, traceability system in the food marketing chain is built. All the links from production to sales, according to the principle can be traced, food production and operation records system are built, and traceability of food quality and safety are realized. So maximum trace to its source, the manufacturers and producers that cause environment risk possibility will be called to account, at the same time, the environmental damage may cause food unsafe product must be recalled easily.

Thirdly, food quality security commitments and defection food recall system are set up. If food is affected by the environmental risk factors, there is "reasonable possibility" thinks the food unsafe, it is unable to meet the specific requirements of commitment, and the producer has an obligation to recall product. At the same time, standards of defective product are established as soon as possible, standardize the procedures of food recall, and establish a perfect food traceability system and recall coordination institution, formulate a set of specific and effective practice, form a scientific and complete recall system, eliminate the dangers of defective food.

Fourthly, a food safety risk analysis, valuation and early warning system are established, at present, our country food safety risk monitoring and evaluation system, just put the food safety risk assessment results as formulate food safety standards, determine the basis of foodborne disease control measures, not to expand risk analysis to the scope of environmental risk prediction, also do not fully consider environmental factors in the risk assessment process, so these food safety 
information, it is not timely, objective, accurate and comprehensive, it can't meet the needs of the public right to know.

Fifthly, food safe public laboratory and food safe early warning system are established. Independent, impartial and authoritative public laboratory should be established, provide a scientific and rigorous technical support food safety and environmental risk control. Real change that only after pollution caused by food safety accident treatment, or caused by food safety pollution, after the media expose, the action will be taken as soon as possible. Ensure control from the source, strengthen prevention, before the accident has not happened they will be killed in the bud.

Sixthly, the social credit system is established and perfected, that is food safety credit file is established, the food quality and food source environmental conditions are tracking and monitoring, form green safe credit system, gradually build environment and food safety win-win survival of the fittest mechanism of the environment and food safety.

Seventh, scientific food safe standards are established. First of all, food safety standards are scientifically treated, through certain risk testing and assessment, in combination with China's national conditions, the practice as the fundamental basis, food safety standards of our country are formulated. Second, ensure the consistency of food safety standards, strive to make the food safety standards system structure reasonable, all kinds of food safety standards scientific supporting coordinate with each other, the most important is to ensure that food safety standards in consistency of various areas and fields in China. Reduce environmental risk caused by food production, processing, sales and transportation. Finally, the dynamic characteristic of the food safety standards should be emphasized. Food safety standard system is not static but dynamic, we should according to the demand of the market and the change of environmental factors, the development trends of science and technology, revise and perfect at any time.

Eighthly, the punishment intensity are increased, the punitive compensation system is established. Given once the food safety and environmental damage happens, the damage is very serious and long, although the current "Food Safety Law" make civil compensation of unqualified food producers from " Law of Protection of the Rights and Interests of Consumers " regulated double increase to 10 times, but because in practice, the circulated ordinary food prices generally is not high (often within dozens of yuan, even a few yuan), increase ten times as much as, it is not more than one thousand yuan, for the manufacturers and sellers, punishment is still little effect. Therefore, it is an urgent need to establish an effective punitive damages system in our country, increase the punishment standard, then effectively protect food safety and environment.

\section{References}

[1] Shouqiu Cai, The study of environmental right, Lgeal Comment of JinLin, 2002 (Spring)-1.J

[2] Shouqiu Cai, The Study on environmental responsibility of the government, the Science of Law of Hebei, 2008-03.

[3] Osuga Akira Right of Existence [C]. Tokyo: Sansendo, 205 (1977).

[4] Wang xi, The environmental law in USA, Wuhan Press, 1992.

[5] Selected Environmental Law Statutes (1999-2000), Educational Edition, West Group, 1999. 